the battered baby largely in the hands of inexperienced field workers and perhaps go some way towards overcoming the present practice of returning these children home, where re-battering often occurs.-I am, etc.,

SELWYN SMITH

University Department of Psychiatry, Queen Elizabeth Hospital, Birmingham

\section{Diseases in the Tropics}

SIR,-I would like to question the relevance of Dr. W. Z. Conco's remarks about the diseases of civilization (11 August, p. 331). We are told that Dr. Conco "saw Africans not only with coronary heart disease but also with nearly $58 \%$ of the conditions listed by Burkitt and $66 \%$ of those listed by Gelfand as rare." This claim cannot be taken seriously until we are given some idea about the clinical criteria for making his diagnosis, the number of patients involved, and an estimate (at least) of the total number of patients seen over the same period. Presumably the age/sex structure of the population in a Zulu rural area was weighted towards women and children with a moderate number of elderly people. If these data are not available perhaps detailed case studies of these patients could be released.

The value of scientific medical terms as a means of communication with patients is doubtful even in the United Kingdom, as accurate medical histories can be obtained only by avoiding medical jargon. If a patient says that he has diverticular disease, toxoplasmosis, scabies, or migraine he should be asked about his symptoms and environment and then examined to permit formulation of a scientific diagnosis. It is irrelevant whethe or not the patient understands the scientific medical term. Table I in Dr. Conco's paper hides the "English medical terms" he tested thus they cannot be evaluated, but tables II and IV suggest that the terms chosen were often diagnoses.

This publication reinforces my fear that our profession becomes trapped by a desire to use respectable medical labels. Clinician must become more honest about the minimal criteria required before making a diagnosis This approach is being tried in our depart ment and it forces the clinician to use more lay terms, which often describe the clinical situation most accurately. Premature labelling with a pseudo-diagnosis is avoided while our "diagnoses" have accepted minimal confidence limits.

I find table III in Dr. Conco's paper interesting because here are some Zulu lay concepts which need detailed exploration with an open mind free from the shackles of Western medical jargon and dogma. For example, a detailed history of the patient's feelings when he is suffering from umkhondo ("trail disease") and study of a series of such patients could prove useful as an exercise in communication and may contribute new medical knowledge to the African scene. Awareness and analysis of lay and witch doctor descriptions of medical problems ${ }^{12}$ are surely the first steps towards resolving any communication difficulties of developing countries.-I am, etc.,

N. C. H. Sтотт

General Practice Unit,

Welsh National School of Medicine,

Welsh 1 Ingle, R. F., South African Medical foumal, 1973,
47,333 .
2 Stott, N. C. H., and Browne, W. M., South
African Medical foumal, 1973, 47, 334.

\section{Thalassaemia in the British}

SIR,-The recent article by Dr. H. H. M Knox-Macauley and others (21 July, p. 150) and the subsequent letter on this tomic from Dr. J. J. Taylor (11 August, p. 353) have prompted me to record my experience on this subject in Canada.

Over the last eight years my laboratory has conducted a search for abnormal haemoglobin variants and for thalassaemias mainly in the provinces of Alberta, Saskatchewan, and Manitoba and has supplied a service to physicians in the last two provinces for the laboratory diagnosis of these conditions. The diagnosis of $\beta$-thalassaemia trait was made in 132 individuals in 105 families in Saskatchewan and Manitoba on the basis of of haemoglobin patterns, including determination of the $\mathrm{HbA}_{2}$ and $\mathrm{HbF}$ levels, test for raised erythrocyte osmotic resistance, and examination of erythrocyte morphology Thirty-five of these persons $(26.5 \%)$ were considered to be of British origin with no ascertainable history of recent intermarriage with persons of Mediterranean, African, or Asian origin. Nineteen of the $52 \beta$-thalassaemics found in Saskatchewan and 16 of the $\mathbf{8 0}$ found in Manitoba were British. In all of them the $\mathrm{HbA}_{2}$ levels were raised (mean $5.4 \%$, S.D. $\pm 1.13 \%$ in the former mean $5.1 \%, S . D . \pm 0.73 \%$ in the latter; mean $2.2 \%$, S.D. $\pm 0.40 \%$ in a control group) while $\mathrm{HbF}$ levels were normal in about half of these subjects and did not exceed $8 \%$ in the rest. These values are in agreement with those of Dr. Knox-Macauley and his collaborators and indicate that the same $\beta$-thalassaemia gene is probably involved in both series. The propositi in nine of the 25 British families with $\beta$-thalassaemia were detected during population studies. No instances of homozygous $\beta$-thalassaemia or of $\alpha$-thalassaemia were found in British subjects.

These results suggest that at least $20 \%$ of all $\beta$-thalassaemias in central Canada are of immigrant British stock and that in nearly half of them the condition is not suspected clinically. I agree with Dr. Taylor that one of the commonest difficulties to be experienced in these cases is in convincing some colleagues of the diagnosis.-I am, etc.

Department of Biochemistry,

F. Vella University of Saskatchewa Saskatoon, Saskatchewan,

Canada

\section{Hyperamylasaemia in Diabetic Ketosis}

SIR,-We were interested to note that Dr. A. H. Knight and his colleagues (21 July, p. 128) have confirmed our original observation $^{1}$ that the serum amylase is often considerably elevated in diabetic ketosis and that this phenomenon is not obviously due to pancreatitis.

We did in fact take the matter a little further by studying serial amylase levels during the course of oral glucose tolerance tests in 60 newly diagnosed and untreated diabetics and 52 controls. The curves in each group were summated and mean ourves con- structed. The results indicated that the amylase level rose in normals but tended to fall in diabetics, and the difference was statistically significant. The rise in the amylase level following an oral glucose load in normal subjects could be explained in several ways. It could be that the pancreas is stimulated, leading to an overflow of pancreatic amylase into the circulation, or that oral glucose is initially taken into the liver and the glucose appearing in the blood could be due to breakdown of liver glycogen with overflow of liver amylase into the circulation. It is not apparent why the amylase should behave differently in diabetics. The very high amylase levels in diabetic ketosis could lead to a massive breakdown of liver glycogen, and it is even possible that the hyperglycaemia is a secondary phenomenon. In this connexion we have often wondered why the blood sugar should be so high in diabetic ketosis when the patient may have been ill for some days possibly with anorexia and vomiting, which should lower the blood sugar, particularly if the patient has continued to take insulin.

Several workers have doubted whether the serum amylase is simply a passive overflow and have speculated that it may have a primary physiological function. The evidence would now seem to be strong enough to conclude that there are definite abnormalities in amylase metabolism in diabetes, and elucidation of the mechanisms involved may throw some further light on the pathogenesis of diabetes.-We are, etc.

R. FnNN

Sefton General Hospital,

S. COPE

1 Finn, R., and Cope, S., Diabetes, 1963, 12, 141.

\section{Significance of Pseudomonas aeruginosa in} Sputum

SIR,-Dr. M. W. Burns's article (18 August, p. 382) draws attention to a problem which is increasing in frequency not only in Australia but also in Britain. I would like to make a few comments.

Though there is a tendenov sometimes towards unnecessary antibiotic therapy when pseudomonas is isolated from sputum, Dr. Burns seems to over-estimate this danger. The difficulty of assessing the significance of any organism cultured from sputum is well recognized, and Pseudomonas aeruginosa is no exception. The present method most commonly used in clinical bacteriology laboratories (in Britain) is an examination of the Gram film in conjunction with the findings on culture. In the absence of pus cells in the film, the isolation of pseudomonas from soutum cannot be regarded as a clear indication for antibiotic therapy. (The report from our laboratory always states whether or not pus cells are present in the specimen.) The 34 cases described without clinical infection, in which the organism was considered to be a commensal, would most likely be in the category of non-purulent specimen and the patient would not automatically be put on antibiotics. Dr. Burns does not seem to take the purulence of the specimen into consideration when assessing the importance or otherwise of the isolated pseudomonas.

Another point is that no mention is made of the in vitro sensitivities of any of the pseudomonas isolated. This would have been 